\title{
Cross-gender judgments of cues and attributes from photographs
}

\author{
JAMES L. PHILLIPS, RONALD D. GORDINEER, and J. ANN SMITH \\ Oklahoma State University, Stillwater, Oklahoma
}

\begin{abstract}
It was hypothesized that judgments about a stimulus person are more dependent upon interpersonal inferences and are less controlled by the actual features of the stimulus as the observer moves from judgments of cues to judgments of dispositional attributes to decisions about how to relate to the stimulus person. The data tend to support this hypothesis for cues versus attributes, but they suggest that a decision about how to relate to the stimulus person is no less under the control of "objective" features of the stimulus person than are attribute judgments. Judgments of physical attractiveness, however, were more similar to cue judgments than to attribute judgments.
\end{abstract}

Psychologists have characterized the impression formation process in terms of three stages (see, e.g., Crano \& Messé, 1982). First, features of a stimulus person are selected or inferred as cues (see, e.g., Krauss, Apple, Morency, Wenzel, \& Winton, 1981). These cues form the basis for inferences through which dispositional characteristics of the stimulus person are integrated with schematic representations provided by the observer (e.g., Jones \& Davis, 1965). In the third stage, the observer integrates these inferred traits to make decisions about how to respond to the stimulus person (e.g., Anderson, 1974).

This three-stage model implies that judgments about the stimulus person are more dependent upon inferences and are less controlled by the stimulus as the observer moves from cues to decisions. Thus, cue judgments (e.g., weight and age) should reflect differences in stimulus persons more than should judgments of personality or interpersonal decisions.

Within this context, there is some ambiguity about global but superficial features such as physical attractiveness. Although research over the last 20 years suggests that judgments of physical attractiveness are cue judgments, the view that "beauty is in the eye of the beholder" persists. Morse and his colleagues (Morse, Gruzen, \& Reis, 1976; Morse, Reis, \& Wolff, 1974) noted that judgments of physical attractiveness have moderate interrater reliabilities and are highly malleable. They suggested that judgments of physical attractiveness require relatively "deep" inferences similar to attribute judgments.

We examined this issue by comparing judgments of physical attractiveness with judgments of both cues, such as height and weight, and attributes, such as goodness, potency, and activity. This analysis addresses the issue of whether judgments of physical attractiveness are more similar to cue judgments or to attribute judgments with

Correspondence should be addressed to J. Phillips at the Department of Psychology, Oklahoma State University, Stillwater, OK 74078. respect to the degree to which they are controlled by the stimulus.

\section{EXPERIMENT 1}

\section{Method}

Subjects. The subjects were 34 students ( 17 male, 17 female) enrolled in introductory psychology during a summer semester at Oklahoma State University.

Materials. The stimulus materials were Polaroid photographs selected from a set of photos of 27 male and 38 female students from an unrelated experiment. In each photo the student was seated. Each photo included the face, torso, and lower body to the knees. All 65 students had agreed to be photographed and had given written informed consent to the use of their photos in subsequent research.

Photos of atypical students (non-Caucasians and students older than $30)$ were eliminated. From the remaining 54 photos $(24$ male and 30 female), photos of 5 male and 5 female students were randomly selected.

Design and Procedure. The subjects were scheduled individually. Each was told that he/she was to rate strangers based on photos. The subjects were given the five cross-gender photos and were asked to examine them and indicate any person he/she recognized. Three males recognized at least one of the stimulus persons and were discarded, leaving 14 males and 17 females.

The five photos were then placed in a random order, independently for each subject, and returned to the subject with five copies of a rating form. The form asked for ratings of the age, height, and weight of the stimulus person and a rating of physical attractiveness. The subject was then asked to imagine going on a date with the stimulus person, and was asked to rate this date on eight semantic differential scales. There were two scales each for evaluation, potency, and activity, and two scales sensitive to the "riskiness" of the date (safe-dangerous, risky-not risky).

The subjects seemed to understand these instructions and typically completed all ratings in $15 \mathrm{~min}$. The purpose of the study was explained, and the subject was dismissed.

\section{Results}

The data were analyzed separately for male and female subjects and for each of the dependent variables using a treatment (photos) $\times$ subjects ANOVA design. Thus, three components of variance were identified for each dependent variable. The photo $\times$ subject effect was the error term for both photos and subjects. 
The results are summarized in Table 1. For male subjects, there was a clear pattern that differentiated cue judgments from attribute judgments. The effects of photos and subjects were statistically significant for all four cues but tended not to be so for attributes. The pattern can best be identified by the relative percent of variance accounted for by photos and by the photos $\times$ subjects interaction. For three of the cues, the percent of variance accounted for by photos exceeded that for attributes. The photos $x$ subjects effect was larger for all of the attributes than for any of the cues. Judgments of physical attractiveness fit the pattern for cues.

For female subjects, the results were less clear. Although percentage of variance accounted for by the photos $\times$ subjects effect tended to be greater for attributes than for cues, the effect of photos was significant only for height and physical attractiveness whereas the effect was significant for three of the four attribute judgments, and the photo effect tended to be larger for attribute judgments than for cue judgments. The percentage of variance accounted for in judgment of physical attractiveness, however, was similar to that for males.

Although it is not possible to separate gender of subjects and stimuli, these gender differences may reflect a greater homogeneity of male photos. This possibility led to Experiment 2.

\section{EXPERIMENT 2}

\section{Method}

Subjects. The subjects were 40 students ( 15 male, 25 female) enrolled in introductory psychology during a fall semester at Oklahoma State University.

Materials. The stimulus materials consisted of photos of 8 male and 8 female subjects from the same photo pool used in Experiment 1. Ini-

Table 1

Percent of Variance Accounted For and $\boldsymbol{F}$ Values for Male and Female Subjects in Experiment 1

\begin{tabular}{|c|c|c|c|c|c|}
\hline \multirow{2}{*}{$\begin{array}{c}\text { Characteristic } \\
\text { Rated }\end{array}$} & \multicolumn{3}{|c|}{ Percent of Variance } & \multicolumn{2}{|c|}{$F$ Value } \\
\hline & Photos & Subjects & $\mathrm{P} \times \mathrm{S}$ & Photos & Subjects \\
\hline \multicolumn{6}{|c|}{ Male Subjects } \\
\hline Age & 22.76 & 45.38 & 31.87 & $9.28 \dagger$ & $5,70 \dagger$ \\
\hline Height & 9.60 & 61.42 & 28.98 & $4.31 \dagger$ & $8.48 \dagger$ \\
\hline Weight & 21.03 & 47.38 & 31.59 & $8.65 \dagger$ & $6.00 \dagger$ \\
\hline Physical Attractiveness & 26.88 & 34.21 & 38.98 & $8.98 \dagger$ & $3.52 \dagger$ \\
\hline Evaluation & 15.81 & 32.56 & 51.63 & $3.98 \dagger$ & $2.52 *$ \\
\hline Potency & 6.30 & 20.88 & 72.81 & 1.13 & 1.15 \\
\hline Activity & 14.05 & 26.62 & 59.32 & $3.08 *$ & 1.80 \\
\hline Risk & 1.35 & 26.29 & 72.36 & 0.24 & 1.45 \\
\hline \multicolumn{6}{|c|}{ Female Subjects } \\
\hline Age & 3.97 & 35.30 & 60.72 & 1.05 & $2.33 *$ \\
\hline Height & 19.55 & 35.19 & 45.26 & $6.91 \dagger$ & $3.11 \dagger$ \\
\hline Weight & 4.46 & 66.11 & 29.43 & 2.42 & $8.99 \dagger$ \\
\hline Physical Attractiveness & 26.12 & 40.04 & 33.83 & $12.35 \dagger$ & $4.73 \dagger$ \\
\hline Evaluation & 27.39 & 19.22 & 53.39 & $8.21 \dagger$ & 1.44 \\
\hline Potency & 19.26 & 11.85 & 68.90 & $4.47 \dagger$ & 0.69 \\
\hline Activity & 16.41 & 19.38 & 64.21 & $4.09 \dagger$ & 1.21 \\
\hline Risk & 11.13 & 12.52 & 76.36 & 2.33 & 0.66 \\
\hline
\end{tabular}

Table 2

Percent of Variance Accounted For and $\boldsymbol{F}$ Values for Male and Female Subjects in Experiment 2

\begin{tabular}{|c|c|c|c|c|c|}
\hline \multirow{2}{*}{$\begin{array}{c}\text { Characteristic } \\
\text { Rated }\end{array}$} & \multicolumn{3}{|c|}{ Percent of Variance } & \multicolumn{2}{|c|}{$F$ Value } \\
\hline & Photos & Subjects & $\mathrm{P} \times \mathrm{S}$ & Photos & Subjects \\
\hline \multicolumn{6}{|c|}{ Male Subjects } \\
\hline Age & 15.05 & 45.47 & 39.48 & $4.96 \dagger$ & $8.06 \dagger$ \\
\hline Height & 25.54 & 35.36 & 39.09 & $8.48 \dagger$ & $6.33 \dagger$ \\
\hline Weight & 29.81 & 52.66 & 17.53 & $22.11 \dagger$ & $21.04 \dagger$ \\
\hline Physical Attractiveness & 51.73 & 21.94 & 26.32 & $25.55 \dagger$ & $5.84 \dagger$ \\
\hline Evaluation & 22.09 & 35.12 & 42.79 & $6.71 \dagger$ & $5.74 \dagger$ \\
\hline Potency & 27.80 & 30.15 & 42.05 & $8.59 \dagger$ & $5.02 \dagger$ \\
\hline Activity & 22.49 & 29.00 & 48.51 & $6.03 \dagger$ & $4.19 \dagger$ \\
\hline Risk & 8.58 & 36 & 55.04 & 2.03 & $4.63 \dagger$ \\
\hline Monetary Decision & 15.14 & 66.31 & 18.55 & $10.61 \dagger$ & $25.03 \dagger$ \\
\hline \multicolumn{6}{|c|}{ Female Subjects } \\
\hline Age & 46.21 & 27.8 & 25 & $35.58 \dagger$ & 7.50 \\
\hline Height & 29 & 21 & 49 & $11.94 \dagger$ & 3.05 \\
\hline Weight & 24.84 & 43.77 & 31.40 & $15.82 \dagger$ & $9.76 \dagger$ \\
\hline Physical Attr & 51.48 & 18.00 & 30.52 & $33.73 \dagger$ & $4.13 \dagger$ \\
\hline Evaluation & 47.56 & 9.86 & 42.55 & $22.36 \dagger$ & 1.63 \\
\hline Potency & 52.49 & 9.81 & 37.19 & $27.85 \dagger$ & $1.82 *$ \\
\hline Activity & 39.92 & 13.68 & 46.41 & $17.20 \dagger$ & 2.06 \\
\hline Risk & 31.00 & 14.17 & 54.83 & $11.31 \dagger$ & $1.81 *$ \\
\hline Monetary Decision & 23.93 & 57.49 & 18.58 & $25.77 \dagger$ & $21.69 \dagger$ \\
\hline
\end{tabular}

tial selection was random, but several substitutions were made in each photo set to increase heterogeneity for each of the four cue dimensions.

Design and Procedure. The design and procedure were identical to Experiment 1, except for the number of stimuli and a final question on the rating form. The subjects were asked to imagine that their "date" with the stimulus person was a "special occasion" for which "you will have to take care of all expenses." The subjects were asked to indicate the maximum amount of money they would spend on such a date.

As in Experiment 1, the subjects who recognized one or more of the stimulus persons were eliminated from the analysis. One male and 4 female subjects were eliminated, leaving 14 male and 21 female subjects.

\section{Results}

The results are summarized in Table 2. As in Experiment 1 , there were significant effects of both photos and subjects for all cue judgments by male subjects. Unlike Experiment 1, these same significant effects were obtained for female subjects. Photo and subject effects were also significant for both groups for attribute judgments, except for the subjects effect for evaluation with female subjects.

The pattern of effect sizes observed for male subjects in Experiment 1 was not as clear in Experiment 2. The photo effect was not uniformly larger for cues than for attributes for either males or females. However, the percentage of variance accounted for by the photos $\times$ subjects interaction was greater for attributes than for cues for males, and, except for height, the same was true for females.

The pattern is clearer when the subject effect is eliminated. This effect indexes the tendency to bias responses in a consistent direction and thus can be disregarded as a response set. For each characteristic judged by each group in both experiments, the magnitude of the photo 
Table 3

Median Photo Effect $\{\mathbf{P} /[\mathbf{P}+(\mathbf{P} \times \mathbf{S})]\}$ by Type of Judgment

\begin{tabular}{lccccc}
\hline & \multicolumn{2}{c}{ Experiment 1 } & & \multicolumn{2}{c}{ Experiment 2 } \\
\cline { 2 - 3 } \cline { 5 - 6 } Judgment & Males & Females & & Males & Females \\
\hline Median Cue & .4041 & .2166 & & .5124 & .5348 \\
Median Attribute & .1356 & .2110 & .3286 & .4951 \\
Decision & & & .4494 & .5629 \\
\hline
\end{tabular}

effect was recomputed by taking the ratio of the variance accounted for by photos to the variance accounted for by photos and photos $\times$ subjects together. Table 3 reports the median photo effect, recomputed in this manner, both for cues and for attributes, along with the comparable effect for the monetary decision. In all cases, the photo effect is smaller for attributes than for cues. The photo effect for the monetary decision is somewhat larger than for attribute judgments, and, for female subjects, is larger than for cue judgments. An almost identical pattern exists when the magnitude of the photo effect is compared for physical attractiveness, evaluation, and monetary decisions.

\section{GENERAL DISCUSSION}

The three-stage model of impression formation holds that relatively “deeper"' inferences about another person are required as an observer moves from cue judgments to attribute judgments to decisions. This model implies that judgments become less stimulus-determined at each stage. The present data provide, at best, only modest support for that view. Table 3 suggests that attribute judgments are less controlled by the "objective" features of the stimulus person than are cue judgments, but that a decision about how to relate to the stimulus person (how much money to spend on a date) is no less under the control of these features than are attribute judgments. This does not mean that decisions of this sort do not involve individual differences. The results in Table 2 show that the percent of variance accounted for by subjects is larger for the monetary decision judgment than for any other judgment. Subjects disagree on the amount to spend, but they agree on the amount to spend, relative to other dates, to a greater extent than they agree on the relative goodness (or potency, or activity, or risk) of such a date.

These studies do tend to resolve ambiguity regarding the status of judgments of physical attractiveness, however. The percent of variance accounted for by photos was at least as high for judgments of physical attractiveness as for judgments of other cues. Thus, it would appear that to whatever extent "beauty is in the eye of the beholder," it is no more so than is apparent age, height, and weight.

\section{REFERENCES}

ANDERSON, N. (1974). Cognitive algebra: Integration theory applied to social attribution. In L. Berkowitz (Ed.), Advances in experimental social psychology (Vol. 7, pp. 1-102). New York: Academic Press.

Crano, W., \& Messé, L. (1982). Social psychology: Principles and themes of interpersonal behavior. Homewood, IL: Dorsey.

Jones, E. E., \& DAvis, K. E. (1965). From acts to dispositions: The attribution process in person perception. In L. Berkowitz (Ed.), $A d$ vances in experimental social psychology (Vol. 2, pp. 219-266). New York: Academic Press.

Krauss, R. M., Apple, W., Morency, N., Wenzel, C., \& Winton, W. (1981). Verbal, vocal, and visual factors in judgments of another's affect. Journal of Personality \& Social Psychology, 40, 312-319.

Morse, S. J., Gruzen, J., \& ReIs, H. (1976). The "eye of the beholder": A neglected variable in the study of physical attractiveness? Journal of Personality, 44, 209-225.

Morse, S. J., ReIS, H. T., \& WolfF, E. (1974). The "eye of the beholder": Determinants of physical attractiveness judgments in the U.S. and South Africa. Journal of Personality, 42, 528-542.

(Manuscript received for publication June 22, 1987.) 